\title{
Effect of Peg-Coated Silver and Gold Nanoparticles on Spirulina platensis Biomass during its Growth in Closed System
}

\author{
Liliana Cepoii ${ }^{1,2}$, Inga Zinicovscaia ${ }^{3,4,5^{*}}$, Ludmila Rudi ${ }^{1}$, Tatiana Chiriac ${ }^{1}$, Ion Rotari ${ }^{1}$, Vitalii \\ Turchenko ${ }^{3,6}$, Svetlana Djur ${ }^{1}$ \\ 1 Institute of Microbiology and Biotechnology, 1, Academiei Str., 2028 Chisinau, R. Moldova; \\ lilianacepoi@yahoo.com, rudiludmila@gmail.com, chiriac_tv@yahoo.com, ioninhopld@gmail.com, \\ djurlana@hotmail.com \\ 2 State University “Dimitrie Cantemir”, 3/1, Academiei Str., 2028 Chisinau, R. Moldova; \\ lilianacepoi@yahoo.com \\ 3 Joint Institute for Nuclear Research, Joliot-Curie Str., 6, 1419890 Dubna, Russia; zinikovskaia@mail.ru, \\ turchenko@jinr.ru \\ 4 Horia Hulubei National Institute for R\&D in Physics and Nuclear Engineering, 30 Reactorului Str. MG-6, \\ Bucharest - Magurele, Romania, zinikovskaia@mail.ru \\ 5 Donetsk Institute of Physics and Technology named after O.O. Galkin of the NASU, 46 Nauki Ave, 03680 \\ Kiev, Ukraine; turchenko@jinr.ru \\ * Correspondence: zinikovskaial@mail.ru; Tel.: (+74962165609 I.Z.)
}

\begin{abstract}
Silver and gold nanoparticles are a promising tool for medical and industrial application, therefore, their ecotoxicity should be carefully examined. The effect of silver $(12 \mathrm{~nm})$ and gold (4.7) nanoparticles coated with polyethylene glycol on Spirulina platensis biomass growth and biochemical composition was investigated. The spirulina cultivation medium was supplemented with nanoparticles in concentration range 0.025-0.5 $\mu \mathrm{M}$. Given concentrations stimulated spirulina biomass growth, while content of proteins, carbohydrates and auxiliary pigments was affected insignificantly by presence of nanoparticles in cultivation medium. The pronounced effect of gold nanoparticles at concentration $0.5 \mu \mathrm{M}$ on the lipids content was observed. TEM images demonstrate that nanoparticles penetrate inside the cell, resulting in ultrastructural changes in cells.
\end{abstract}

Keywords: Spirulina platensis, silver nanoparticles, gold nanoparticles, spirulina growth, biochemical composition, cell ultrastructure.

\section{Introduction}

Engineered nanoparticles are increasingly used in industry and medicine due to their advantageous properties inherent to their very small sizes, and most of them have been already marketed for years [1]. Metallic nanoparticles are widely exploited for different applications and among them silver (AgNPs) and gold (AuNPs) nanoparticles are highly remarkable [2].

Silver nanoparticles due to their physical, optical, chemical, antimicrobial properties are excellent candidates for many purposes such as cancer treatment, molecular detection and diagnosis, transportation of the drugs, etc. [3- 5]. Nowadays, AgNPs are used in in textile engineering, in electronics, in optics, in medical devices, as well as in different consumer products (in air sanitizer sprays, pillows, respirators, socks, wet wipes, detergents, soaps, shampoos, toothpastes, washing machines, etc) [6, 7]. Another aspect of AgNPs application is related to their activity as biosensor and regulators of metabolism in plants $[8,9]$. 
Unique properties of AuNPs have resulted in their application in different domains, especially in medicine. They have suitable properties for controlled targeted drug delivery, imaging, photothermal and photodynamic therapy, detection of cancer cells, and cancer treatment [2, 10-12]. AuNPs are also widely applied in optoelectronics, photonics, catalysis, imaging technology, space science, etc. [13].

The exponential production and utilization of nanoparticles raises environmental concerns owing to their potential harmful effects on natural environments and human health [1]. The nanoparticles can exhibit toxicity to living organisms mainly because of their small size $(>100 \mathrm{~nm})$, large surface-to-volume ratio and highly reactive facets [14]. Since nanoparticles have the same dimensions as biological molecules they can damage DNA, denature proteins and enzymes and produce free radicals [3]. In human and animals, nanoparticles easily penetrate the circulatory system are accumulated in different organs and even translocate the blood-brain barrier [6, 15].

The microorganisms including cyanobacteria present in the natural ecosystem are the primary targets that get exposed to nanoparticles. Cyanobacteria have several important functions in aquatic and terrestrial ecosystems including $\mathrm{CO}_{2}$ and $\mathrm{N}_{2}$ fixation, oxygen evolution, biomass production. They are considered as primary producers of organic compounds [16]. Cyanobacteria have gained much attention as a rich source of bioactive compounds and have been considered as one of the most promising groups of organisms to produce them [17].

As a biological test organism cyanobacteria Spirulina platensis was used. Spirulina contains a unique physiologically balanced combination of substances, vital for human: $60-70 \%$ protein, $10-20 \%$ carbohydrates, $5 \%$ fat, $0.9 \%$ chlorophyll, and also vitamins, minerals, carotenoids, etc. (about 50 items in total) and is one of the few sources of dietary $\gamma$-linolenic acid (GLA) [18, 19]. Effect of metal nanoparticles on cyanobacteria was described in several papers [16, 20-22]. However, in the main part of the research devoted to nanoparticles toxicity the effect of high concentration of metal nanoparticles on living organisms was investigated.

The objective of the present study was to study the influence of low concentrations (0.025 - 0.5 $\mu \mathrm{M})$ of PEG-coated AgNPs and AuNPs nanoparticles on the growth and biochemical composition of Spirulina platensis biomass during its cultivation in the closed system.

\section{Materials and Methods}

\subsection{Nanoparticles}

Polyethylene glycol coated silver (PEG-AgNPs) and gold (PEG-AuNPs) nanoparticles used in this study were purchased from M9 company (Tolyatti, Russia).

\subsection{Object of study}

As the object of study, Spirulina platensis CNMN CB-02 strain from the National Collection of Nonpathogenic Microorganisms of the Institute of Microbiology and Biotechnology was used.

\subsection{Experiment design}

Spirulina platensis Nordst (Geitl) CNMN-CB-02 biomass was grown in the cultivation medium with the following composition: macroelements $(\mathrm{g} / \mathrm{L})-\mathrm{NaNO}_{3}-2.5 ; \mathrm{NaHCO}_{3}-8.0 ; \mathrm{NaCl}-1.0 ; \mathrm{K}_{2} \mathrm{SO}_{4}-1.0$; $\mathrm{Na}_{2} \mathrm{HPO}_{4}-0.2 ; \mathrm{MgSO}_{4} \cdot 7 \mathrm{H}_{2} \mathrm{O}-0.2$; and microelements (mg/ml medium): $\mathrm{H}_{3} \mathrm{BO}_{3}-2.86$; $\mathrm{MnCl}_{2} \cdot 4 \mathrm{H}_{2} \mathrm{O}-1.81$; $\mathrm{CuSO}_{4} \cdot 5 \mathrm{H}_{2} \mathrm{O}-0.08 ; \mathrm{MoO}_{3}-0.015 ; \mathrm{FeEDTA}-1 \mathrm{ml} / \mathrm{L}$. The spirulina was cultivated in Erlenmeyer flasks of $500 \mathrm{ml}$ volume with culture volume $250 \mathrm{ml}$ for six days fulfilling the optimal conditions of biomass growth: temperature $30 \pm 1{ }^{\circ} \mathrm{C}, \mathrm{pH}$ 8-10 and illumination 37-55 $\mu \mathrm{M}$ photons $/ \mathrm{m}^{2} \mathrm{~s}$. AgNPs and AuNPs were supplemented to cultivation medium in concentration range from 0.025 to $0.5 \mu \mathrm{M}$ in the first day of biomass cultivation. On stationary growth phase ( $6^{\text {th }}$ day) the cyanobacteria biomass was separated from the culture medium by filtration and used for further analysis.

Quantitative parameters evaluated after experiments were biomass quantity, content of proteins, phycobilins, carbohydrates, $\beta$-carotene and chlorophyll a, lipids and malondialdehyde (MDA). Obtained values for biomass were expressed in $\mathrm{g} / \mathrm{L}$ and for other components - in percentages of dry biomass, and compared with values obtained for control biomass (spirulina growing in standard culture medium without addition of nanoparticles). 


\subsection{Biochemical analysis}

Biomass quantity was determined spectrophotometrically (T80+UV/VIS Spectrometer, PG Instruments LTD, UK), with recalculation of the mass of cells to absolutely dry biomass (ADB), according the method described in [23]. For proteins extraction $10 \mathrm{mg}$ of biomass was mixed with 0.9 $\mathrm{mL} \mathrm{NaOH}$ (concentration $0.1 \mathrm{~N}$ ) for $30 \mathrm{~min} .0 .1 \mathrm{~mL}$ of the obtained protein extract was mixed with 1.6 $\mathrm{mL}$ of $\mathrm{Na}_{2} \mathrm{CO}_{3}(2 \%)$ in $\mathrm{NaOH} 0.1 \mathrm{~N}, 0.4 \mathrm{~mL}$ of $\mathrm{CuSO}_{4}(0.5 \%)$ in $\mathrm{Na}_{3} \mathrm{C}_{6} \mathrm{H}_{5} \mathrm{O}_{7}(1 \%)$ and $0.2 \mathrm{~mL}$ of FolinCiocalteu reagent. After $30 \mathrm{~min}$ the absorbance was measured at $750 \mathrm{~nm}$. The protein content was determined using a calibration curve for bovine serum albumin. Phycobiliprotein content was determined spectrophotometrically in water extract $(10 \mathrm{mg}$ of wet biomass was mixed with $10 \mathrm{~mL}$ of distillated water). The absorbance of supernatant separated from the culture medium by centrifugation was measured at 620 and $650 \mathrm{~nm}$. Phycobiliprotein content was calculated using molar absorption coefficient for phycocyanin and allophycocyanin. To determine carbohydrates content, $0.25 \mathrm{~mL}$ of the sample was mixed with $2.5 \mathrm{~mL}$ of Antrone reagent $(0.5 \%)$ in $\mathrm{H}_{2} \mathrm{SO}_{4}(66 \%)$. The mixture was incubated at $1000 \mathrm{C}$ for $30 \mathrm{~min}$. The absorbance was measured at $620 \mathrm{~nm}$. Carbohydrates content was calculated using a calibration curve for glucose. Lipids content was determined spectrophotometrically on the basis of the lipids degradation using fosfovanilinic reagent. Hydrolysis of the lipids ( $10 \mathrm{mg}$ biomass) was produced by sulfuric acid at $100^{\circ} \mathrm{C}$. Obtained hydrolysate $(0.5 \mathrm{~mL})$ was mixed with $1.5 \mathrm{~mL}$ fosfovanilinic reagent. After $45 \mathrm{~min}$ the absorbance was measured at $560 \mathrm{~nm}$. Lipids content was calculated using calibration curve. The content of aforementioned biomolecules was expressed in $\%$ of absolute dry biomass. $\beta$ - carotene and chlorophyll a were determined spectrophotometrically in ethanolic extract as is indicated in [24]. The MDA content was determined spectrophotometrically based on the reactive products of thiobarbituric acid. Absorbance was measured at $532 \mathrm{~nm}$ (the maximum absorbance for the MDA-TBA complex) and at $600 \mathrm{~nm}$ (for the correction of the non-specific turbidity).

All measurements were performed in triplicate an $\mathrm{d}$ the average values were used.

\subsection{Methods}

The zeta potential of nanoparticles was determined by photon correlation spectroscopy (PCS) using a Zetasizer Nano ZS system (Malvern Instruments, Malvern, UK). The phase composition as well as type of crystal structure of the nanoparticles have been analyzed by $\mathrm{X}$-ray diffractometer EMPYREAN (firm PANalytical) in Cu-K $\alpha$ radiation $\lambda=1.541874 \AA$ A. The powder diffraction software package HighScore Plus [The HighScore suite] which includes the standards of the ICDD (http://www.icdd.com/) was used to identify and to refine crystal structures with Rietveld analysis (Rietveld, 1969).

The morphology of spirulina cells before (control) and after exposure to nanoparticles (experiment) was characterized by transmission electron microscopy (TEM) using a JEM-1400 microscope («Jeol», Japan) at accelerating voltage of $100 \mathrm{~kW}$.

\section{Results}

\subsection{Nanoparticles characterization}

The zeta potential values determined for analyzed nanoparticles constituted - $12.1 \mathrm{mV}$ for PEGAgNPs and -27.2 mV for PEG-AuNPs, thus indicating a high stability of the colloidal system. The Xray diffraction method was used to examine the PEG-AgNPs and PEG-AuNPs and obtained XRD patterns are shown in Fig. 1. 

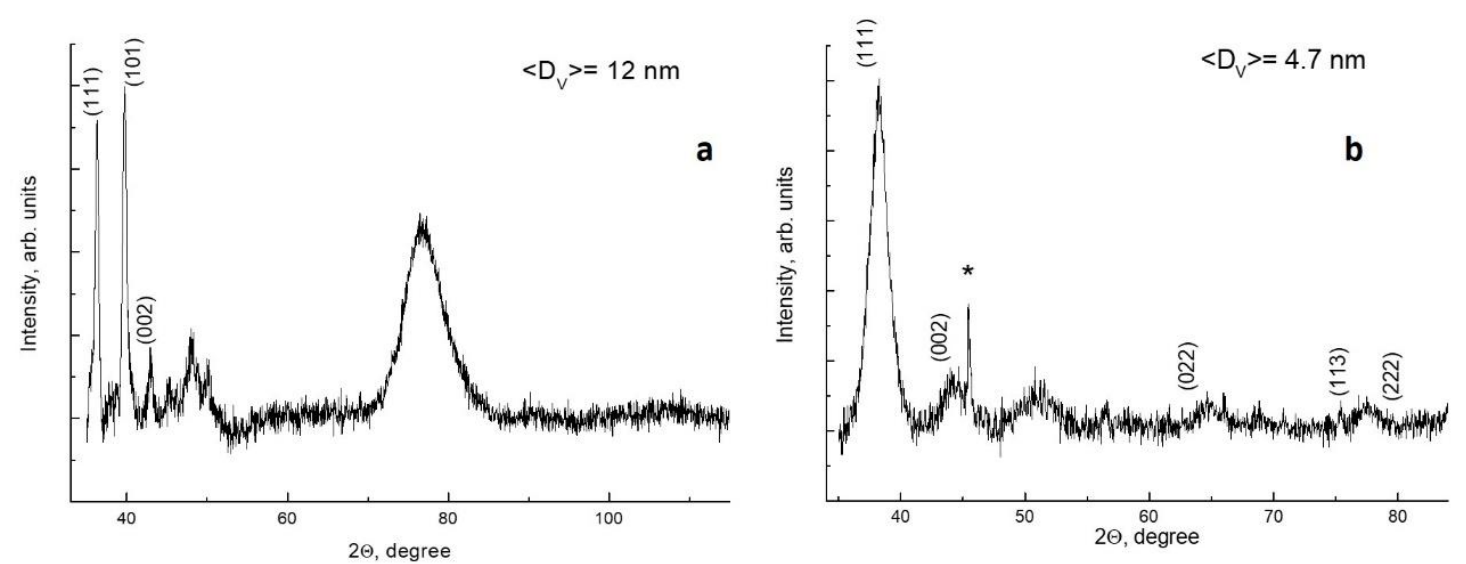

Figure 1 X-ray diffraction patterns of a) AgNPs and b) AuNPs measured at room temperature and fitted by the

\section{Rietveld method}

In diffractogram obtained for AgNPs are present silver crystals of cubic (Ag XRD Ref. 98-0426921) [25] and hexagonal (Ag XRD Ref. 01-071-5025) [26] forms. Characteristic peaks (111) and (002) corresponds to cubic form, while peak (101) to hexagonal form. The wide peak in area $70-90^{\circ}$ can be attributed to the overlapping of characteristic peaks of cubic and hexagonal forms. In case of PEGAuNPs the peaks in $38.08^{\circ}, 44.26^{\circ}, 64.38^{\circ}, 77.31^{\circ}$ and $81.45^{\circ}$ can be attributed to the (111), (002), (022), (113) and (222) crystalline structures of the face centered cubic gold (Au XRD Ref. 98-005-3763).

The Scherrer equation was used to determine the average size of crystallites.

$$
<\mathrm{D}>=\mathrm{K} \lambda / \beta \cos \theta
$$

where $\mathrm{K}$ is the shape factor, which for cubic crystals it is $\sim 0.9 ; \lambda$ is the $\mathrm{X}$-ray wavelength for $\mathrm{Cu}-\mathrm{K} \alpha$; $\beta$ is the line broadening at half the maximum intensity in radians; $\theta$ is the Bragg angle, and $D$ is the size of a nanoparticle in $\AA$.

According to calculated data the average size of AuNPs is $\sim 4.7 \mathrm{~nm}$, while of AgNPs $\sim 12 \mathrm{~nm}$. Since both type of nanoparticles were PEG-coated in the further discussion terms AgNPs and AuNPs were used.

\subsection{Effect of silver nanoparticles on Spirulina platensis growth}

Introduction of AgNPs in cultivation medium in concentration range $0.025-0.1 \mu \mathrm{M}$ produced favourable effects on spirulina biomass, resulting in its increase by $24.2-31.6 \%$ in comparison with control (Fig. 2). At AgNPs concentrations 0.25 and $0.5 \mu \mathrm{M}$ biomass increased by 18.9 and $14.7 \%$, respectivly.

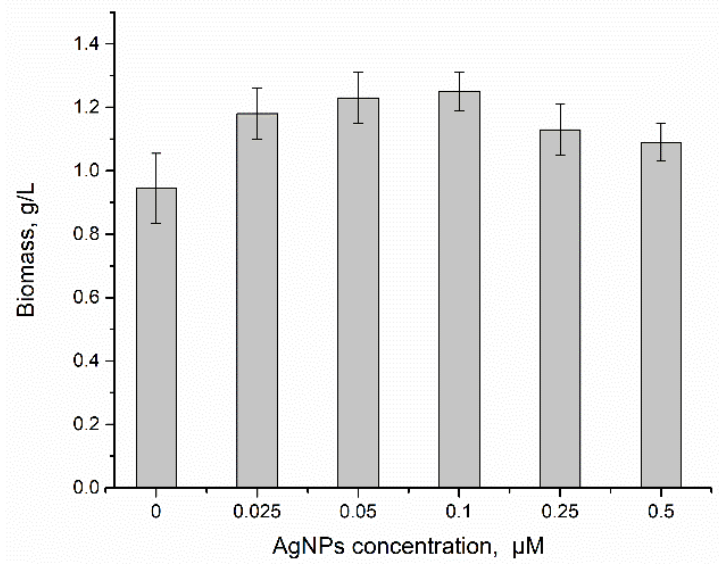

Figure 2. Spirulina platensis biomass at introduction of AgNPs in cultivation medium in concentration range $0.025-0.1 \mu \mathrm{M}$ 
At AgNPs concentrations in medium 0.05 and $0.1 \mu \mathrm{M}$ a slight increase of proteins content by 7.0 and $9.5 \%$, respectively takes place. At other concentrations increase of proteins content was insignificant. The carbohydrates content in control biomass constituted 9.6\%. Introduction of AgNPs in cultivation medium at given concentrations did not affected their content in biomass, which lies between 8.64 and $9.54 \%$ (Fig. 3). The amount of primary and secondary photosynthetic pigments (chlorophyll a, $\beta$-carotene and phycobilins) did not change significantly under the action of AgNPs in studied range of concentrations. Thus, the content of phycobolins in spirulina biomass varied from 10.9 to $13.8 \%$ that fell whitin the values characteristic for native spirulina biomass (Fig. 3). The content of phycobolins in control biomass was $12.1 \%$.
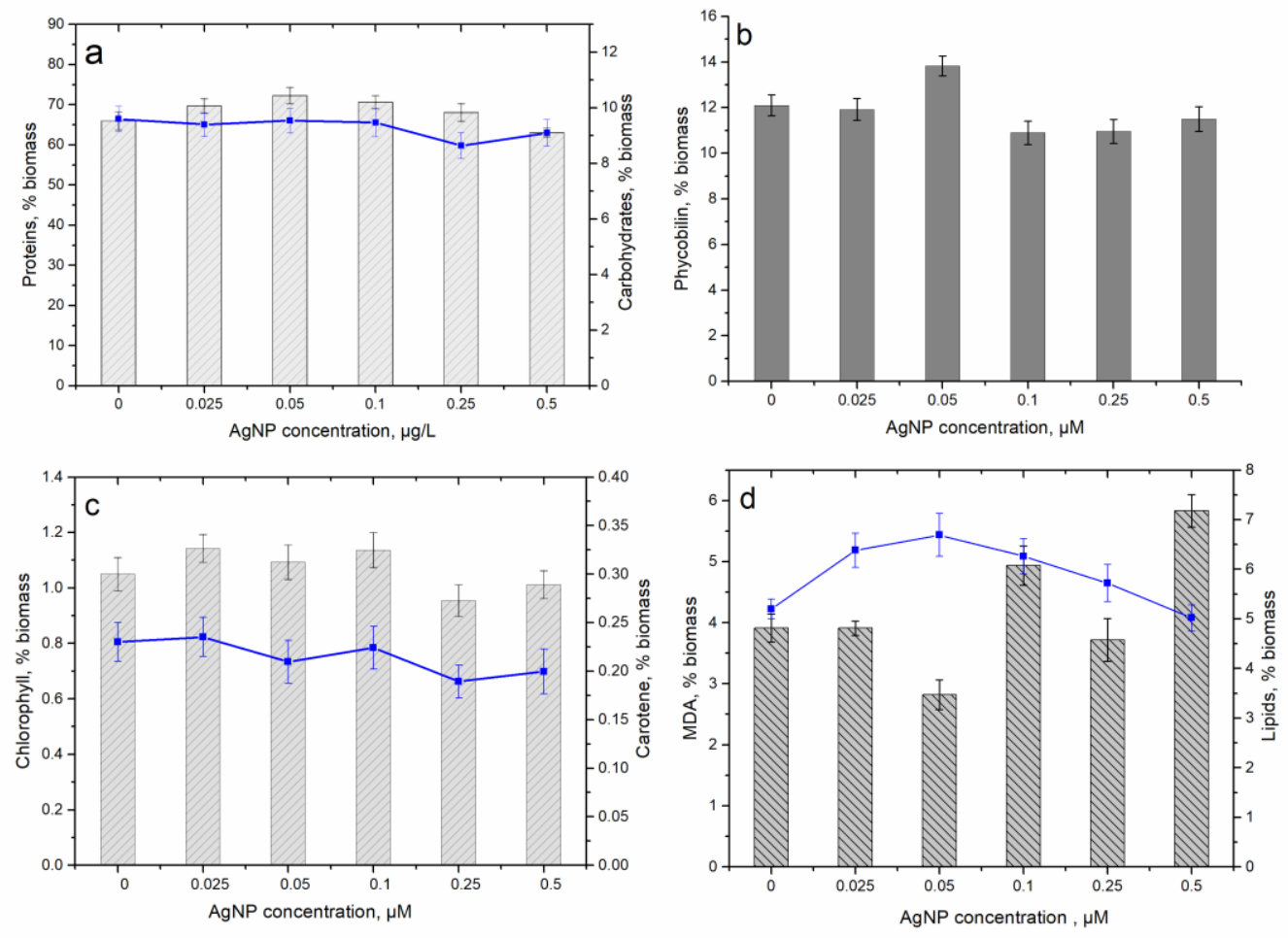

Figure 3 Change of a) proteins and carbohydrates, b) phycobilins, c) $\beta$-carotene and chlorophyll a and d) lipids and MDA content in Spirulina platensis biomass at introduction of AgNPs in cultivation mediu in concentration range $0.025-0.1 \mu \mathrm{M}$

The oscillations of the contents of the two pigments ( $\beta$-carotene and chlorophyll a) were very similar. The content of chlorophyll a in AgNPs supplemented biomass varied from 0.95 to $1.14 \%$ of biomass, variation being statistically insignificant. And in the case of $\beta$-carotene, which values varied from 0.19 to $0.24 \%$ of biomass the variations were also minor (Fig. 3).

The components whose content changed signifficanly under AgNPs action were lipids. At AgNPs concentration in solution $0.025-0.1 \mu \mathrm{M}$ the increase of their content by $20.3-28.6 \%$ in comparison with control biomass was observed (Fig. 3). The content of lipids oxidation products malondialdehyde (MDA) showed the tendency of increase at AgNPs concentrations 0.1 and $0.5 \mu \mathrm{M}$ by 26.2 and $49.2 \%$, respectively in comparison with control biomass.

\subsection{Effect of gold nanoparticles on Spirulina platensis growth}

Introduction of AuNPs in the cultivation medium in the concentration range $0.025-0.5 \mu \mathrm{M}$ has a positive effect on spirulina biomass growth (Fig. 4). Thus, biomass productivity increased by $29.4-35.8 \%$ in comparison with control biomass. 


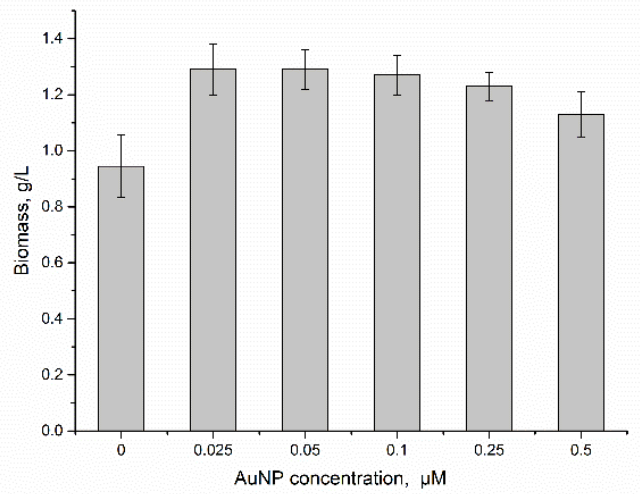

Figure 4. Spirulina platensis biomass at introduction of AuNPs in cultivation medium in concentration range

$$
0.025-0.1 \mu \mathrm{M}
$$

The content of proteins in biomass was not influenced by the presence of AuNPs in the cultivation medium, and varied between 64.6 and 69.7\% (Fig. 5). The same applies to carbohydrates, which content in biomass was not affected by AuNPs presence and was within $8.8-9.8 \%$. The carbohydrates content in biomass was $9.6 \%$.
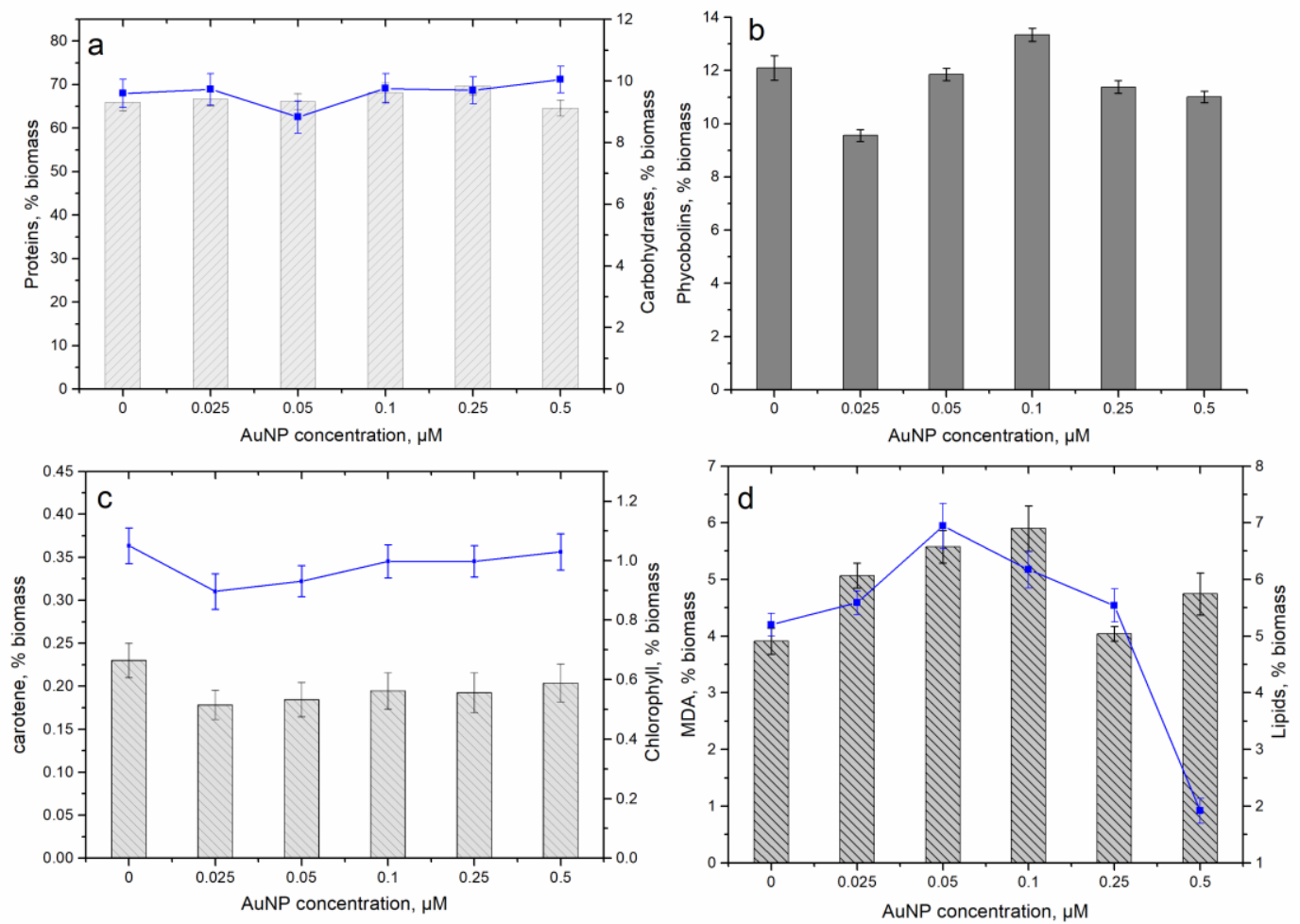

Figure 5. Change of a) proteins and carbohydrates, b) phycobilins, c) $\beta$-carotene and chlorophyll a and d) lipids and MDA content in Spirulina platensis biomass at introduction of AgNPs in cultivation medium in concentration range $0.025-0.1 \mu \mathrm{M}$

At AuNPs concentration in solution $0.025 \mu \mathrm{M}$ the content of phycobilins in biomass decreased by $21 \%$, while at concentration $0.1 \mu \mathrm{M}$ it increased by $10 \%$. Other concentrations of AuNPs have not affected phycobilins content and it remained at the level of control biomass $(12.1 \%)$. The content of $\beta$-carotene and chlorophyll a changed in the same way. The lowest AuNPs concentration of 0.025$0.05 \mu \mathrm{M}$, induced the decrease of content of $\beta$-carotene by $19.8-22.5 \%$, and of chlorophyll a by $11.3-$ $14.7 \%$ in comparison with native biomass (Fig. 5). At concentration range of $0.1-0.5 \mu \mathrm{M}$ the decrease 
of $\beta$-carotene by $8.4-16.3 \%$ was noticed. AuNPs concentrations $0.1-0.5 \mu \mathrm{M}$ did not influence significantly chlorophyll a content, it decreased by $1-6 \%$.

The increase of lipids content by 33.5 and $18.7 \%$, respectively was noticed at AuNPs concentrations 0.05 and $0.10 \mu \mathrm{M}$. Instead, at AuNPs concentration $0.5 \mu \mathrm{M}$ the drastic decrease of lipids content by $63.1 \%$ in comparison with native biomass takes place (Fig. 5). The increase of MDA content in the AuNPs concentration range $0.025-0.1 \mu \mathrm{M}$ by $29.5-50.8 \%$ in comparison with control biomass was noticed. The increase of MDA content was also observed at AuNPs concentration 0.5 $\mu \mathrm{M}$ by $21.3 \%$ in comparison with control biomass, what is relevant, especially taking in the account the reduced content of lipids in biomass.

\subsection{Transmission electon microscopy}

As can be observed from the TEM images (Fig. 6) exposure to AgNPs and AuNPs led to ultrastructural changes of the cells, depending on concentration of nanoparticles. Micrographs of control cells showed an intact cell wall, very thin capsule, compact thilakoids, a large number of carboxysomes. Under the influence of nanoparticles, the cell wall becomes diffuse. The thilakoids in control cells are presented by a large number of dense lamellae. Nanoparticles produce a partial degradation of thilakoids. In control and AgNPs $(0.05 \mu \mathrm{M})$ supplemented biomass the large number of carboxysomes, polyhedral inclusion bodies that contain the enzyme ribulose 1.5-diphosphate carboxylase/oxidase (RuBisCO), responsible for carbon dioxide fixation in spirulina, was observed. In AuNPs $(0.05 \mu \mathrm{M})$ and in AgNPs $(0.5 \mu \mathrm{M})$ supplemented biomass these inclusion bodies are missing, that indicate on lower efficiency of ribulose 1.5-diphosphate carboxylase and consequently of carbon fization, because the efficiency of 1.5-diphosphate carboxylase is quite reduced, and the compartmentalization of the enzyme in carboxysome is the mechanism of carbon dioxide concentration with the scope of its fixation.
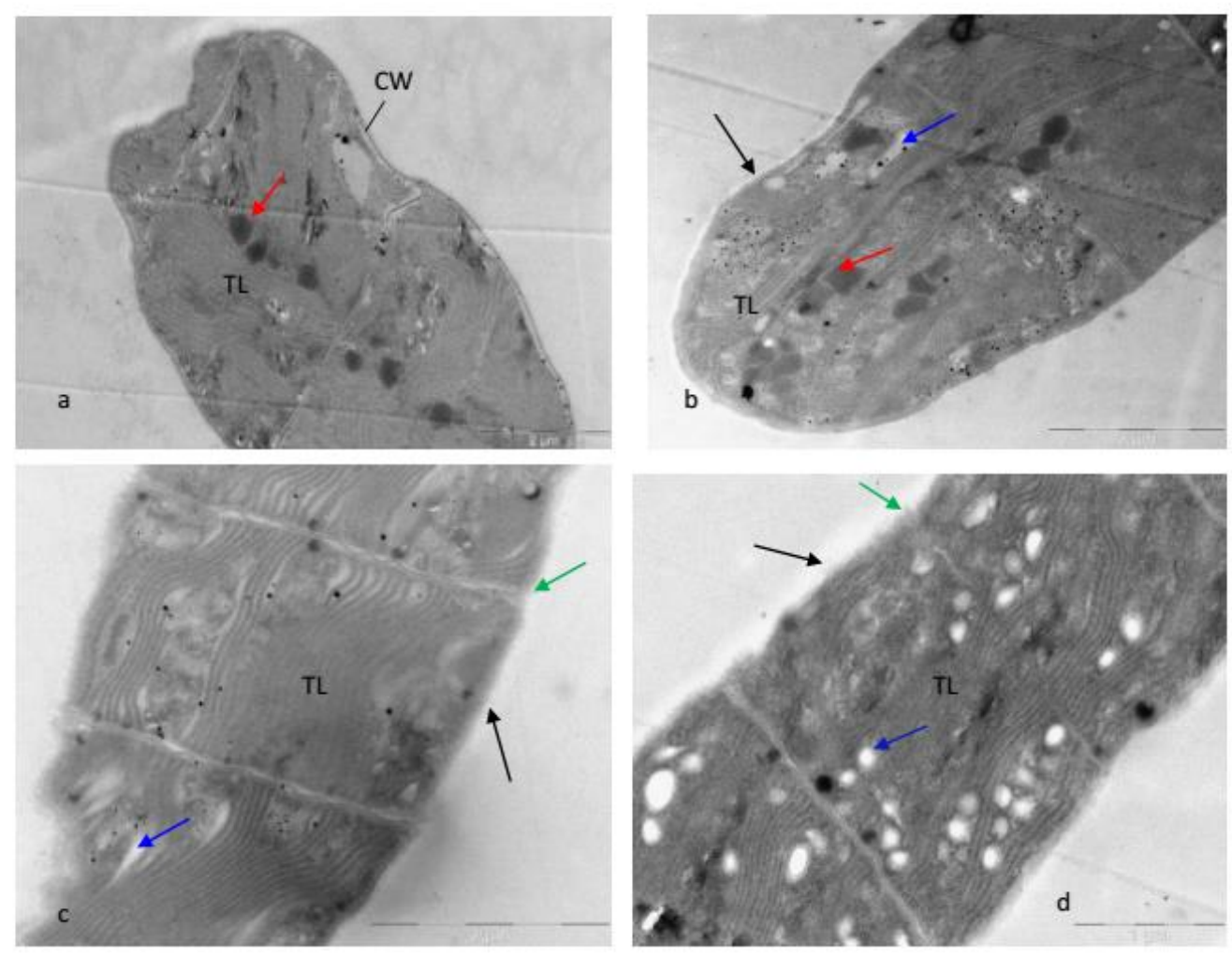

Figure 6. Transmission electron microscopy images of Spirulina platensis a) control, b) exposed to $0.05 \mu \mathrm{M}$ AgNPs, c) exposed to $0.05 \mu \mathrm{M}$ AuNPs, and d) exposed to $0.5 \mu \mathrm{M}$ AgNPs (red arrows indicate carboxysomes; blue - vacuolizated space, green - membrane rupture, black - exopolysaccharides layer, TL - thylakoids, CW cell wall). 


\section{Discussion}

According to literature data mechanisms of metal nanoparticles toxicity can be associated with generation of oxygen species (ROS), DNA damage, disturbances in the cellular phosphate management, denaturation of ribosomes, etc. Often AgNPs toxicity is attributed to the formation of $\mathrm{Ag}^{+}$ions, which easily interact with thiol groups and proteins, inactivating enzymes [27-29]. The toxicity of AgNPs in general, is lower than toxicity of silver ions. For example, the toxicity of AgNPs of $25 \mathrm{~nm}$ size to Chlamydomonas reinhardtii was 18 times lower than of $\mathrm{Ag}^{+}$ions [30]. The toxicity effect of polyvinylpyrrolidone (PVP)-stabilized silver nanoparticles, of size $70 \mathrm{~nm}$, toward Escherichia coli, Staphylococcus aureus, human mesenchymal stem cells, and peripheral blood mononuclear cells was a factor of 20 to 30 less pronounced than that of silver ions [31]. However, AgNPs toxicity is strongly dependent of nanoparticles size, shape, coating and concentration. It was shown, that AgNPs with size less than $5 \mathrm{~nm}$ were more toxic to nitrifying bacteria than nanoparticles of other size or their counterpart bulk species [27].

In the present study at AgNPs $(12 \mathrm{~nm})$ concentration range $0.025-0.5 \mu \mathrm{M}$ cell viability and biomass biochemical composition was not affected significantly by the nanoparticles addition in the cultivation medium. Obtained data are in agreement with results presented by Pinzaru et al. [32], who showed a lack of toxicity of AgNPs at concentrations lower than $10 \mu \mathrm{M}$. The lack of toxic effect of AgNPs to cells in present study can be explained by AgNPs coating with polyethylene glycol (PEG). In Bastos et al. [33] and Pinzaru et al. [32] studies it was shown that PEG-coated AgNPs showed a lesser degree of toxicity to HaCat cells as compared to bare AgNPs and NPs with other type of coating. At given concentrations AgNPs did not change or produce a slight increase of the proteins, carbohydrates, $\beta$-carotene and chlorophyll a content in spirulina biomass. The carbohydrates play important role in cell protection against different pollutants, including nanoparticles. This compounds produced by cyanobacteria can surround the cells as capsules and prevent nanoparticles penetration inside the cell $[34,35]$. The phycoblins are biomass components, which are reacting promptly to pollutants impact and in case of pronounced toxic effect, their content in biomass significantly decrease. In performed experiments the content of phycobilins modification was less evident, indicating on lack of nanoparticles toxic effect on spirulina biomass. The decrease of content of lipids and increase of the MDA content at AgNPs concentration $0.5 \mu \mathrm{M}$ can be associated with oxidative degradation of lipids. Thus, the possible toxic effect of AgNPs on spirulina biomass can be assumed. In [33] it was shown that uptake of PEG-coated AgNPs can be associated with their partially dissolution that lead to the formation of $\mathrm{Ag}^{+}$ions. Thus, it can be concluded that lipids are mainly affected by PEG-coated AgNPs.

In general, it is considered that toxicity of AuNPs for living organisms is lower than that of AgNPs. However, as in case of AgNPs their toxicity is strongly dependent of factors such as shape, size, concentration, surface charge, coating, and surface [36]. There are numerous report proving the toxicity of AuNPs to living organisms. For example, the toxicity of $4 \mathrm{~nm}$ polyallylamine hydrochloride-wrapped gold nanoparticles to a panel of bacteria from diverse environmental niches (Azotobacter vinelandii, Acinetobacter baylyi, Shewanella oneidensis, Pseudomonas aeruginosa) is expressed by the different minimum bactericidal concentrations determined $(0.028-2.8 \mathrm{ppm})$ [37]. AuNPs showed to be toxic to fungal species Aspergillus niger, Mucor hiemalis, and Penicillium chrysogenum, and the level of their toxicity was determined by NPs shape and size. Thus, larger and non-spherical AuNPs had relatively stronger toxicities against fungi [38]. AuNPs with the size range of 0.8-10.4 nm were tested for their antibacterial activity against pathogenical species. AuNPs with core diameters of 0.8 and $1.4 \mathrm{~nm}$ and a triphenylphosphine-monosulfonate shell have minimum inhibitory concentration and minimum bactericidal concentration of $25 \mu \mathrm{M}$ against Staphylococcus aureus, Staphylococcus epidermidis, Escherichia coli and Pseudomonas aeruginosa. At the same time, similar sized thiol-capped AuNPs were nontoxic even at 32-fold higher concentrations. AuNPs toxicity was associated with loss in the membrane permeability [39]. The pegylated AuNPs were found to be less toxic for the alga Pseudokirchneriella subcapitata compared to amphiphilic coated particles [40]. At the same time according to Lehmann et al. [41] the toxicity of coated-AuNPs arises from the Au core rather than from the polymer shell. 
AuNPs at concentration $0.025-0.5 \mu \mathrm{M}$ had a positive effect on biomass growth and did not influence significantly proteins and carbohydrates content. At low concentrations of AuNPs the content of $\beta$-carotene, phycobilins and chlorophyll a in biomass decreased by more than $20 \%$. With increase of concentration up to $0.5 \mu \mathrm{M}$ the content of accessory pigments in AuNPs supplemented biomass has not change significantly. Instead, at AuNPs concentration $0.5 \mu \mathrm{M}$ the drastic decrease of lipids content by $63.1 \%$ in comparison with native biomass takes place. Thus, the deviation from normal metabolism of lipids is evident (Fig. 5). Coated AuNPs easily penetrate into the hydrophobic moiety of the lipid bilayers and cause membrane disruption at increased concentration [42].

According to images obtained by TEM both, AgNPs and AuNPs caused a pronounced vacuolization of the cytoplasm, especially AgNPs at concertation $0.5 \mu \mathrm{M}$. Also, the accumulation of nanoparticles leads to the release of a larger amount of extracellular polymers, which form a more pronounced layer of exopolysaccharides. Therefore, as it was mentioned below, external layers of polysaccharides play protective role against the toxic compounds and can be can be regarded as the protective mechanism.

\section{Conclusions}

Silver and gold nanoparticles in concentration range $0.025-0.5 \mu$ M have a stimulating effect on spirulina biomass accumulation (by 31.6 and $35.8 \%$, respectively). Both type of NPs did not alter significantly the content of proteins, carbohydrates and pigments. The content of lipids was changed significantly in NPs supplemented biomass by increase of their content at AgNPs concentrations of 0.025, 0.05 and $0.1 \mu \mathrm{M}$ and at AuNPs concentrations of 0.05 and $0.1 \mu \mathrm{M}$, and decrease at AuNPs concentration of $0.5 \mu \mathrm{M}$. High levels of MDA in NPs-supplemented biomass are associated with the increase of the lipids content in biomass. However, at AuNPs concentration of $0.5 \mu \mathrm{M}$ high MDA quantity is a possible stress indicator under a minimal lipid level. The exposure to AgNPs and AuNPs resulted in ultrastructural changes of the cells, expressed in membrane and cell wall ruptures, partial degradation of tilacloids, absence of carboxysomes, more pronounced vacuolization of the cytoplasm, release of a larger amount of extracellular polymers, which form thick layer of exopolysaccharides. Obtained results indicate on the potential hazard of studied nanoparticles and the need to study in depth the mechanisms of nanomaterials effect on living organisms.

Author Contributions: Conceptualization, L.C. and I.Z.; methodology, L.C., I.Z., L.R., T.C.; biochemical tests performance L.R., T.C., S. D., I.R.; XRD measurements V.T.; TEM analysis I.Z., L.C.; validation, L.C., L.R.; investigation, L.C.; resources, S.D; data curation, L.R., T.C.; writing-original draft preparation, L.C. and I.Z.; writing-review and editing, L.C. and I.Z. 11 authors have read and agreed to the published version of the manuscript.

Funding: This research received no external funding

Conflicts of Interest: The authors declare no conflict of interest 


\section{References}

In the text, reference numbers should be placed in square brackets [ ], and placed before the punctuation; for example [1], [1-3] or [1,3]. For embedded citations in the text with pagination, use both parentheses and brackets to indicate the reference number and page numbers; for example [5] (p. 10), or [6] (pp. 101-105).

1. Planchon, M.; Jittawuttipoka, T.; Cassier-Chauvat, C.; Guyot, F.; Gelabert, A.; Benedetti, M.F.; Chauvat, F.; Spalla, O. Exopolysaccharides protect Synechocystis against the deleterious effects of titanium dioxide nanoparticles in natural and artificial waters. Journal of Colloid and Interface Science 2013, 405, 35-43. https://doi.org/10.1016/j.jcis.2013.05.061

2. Elahi, N.; Kamali, M.; Baghersad, M.H. Recent biomedical applications of gold nanoparticles: A review. Talanta 2018, 184, 537-556. https://doi.org/10.1016/j.talanta.2018.02.088

3. Chaloupka, K.; Malam, Y.; Seifalian, A.M. Nanosilver as a new generation of nanoproduct in biomedical applications. Trends in Biotechnology 2010, 28, 580-588.

https://doi.org/10.1016/j.tibtech.2010.07.006

4. Chen, H.; Gao, F.; He, R.; Cui, D. Chemiluminescence of luminol catalyzed by silver nanoparticles. Journal of Colloid and Interface Science 2007, 315, 158-163. https://doi.org/10.1016/j.jcis.2007.06.052

5. Nair, L.S.; Laurencin, C.T. Silver nanoparticles: Synthesis and therapeutic applications. Journal of Biomedical Nanotechnology 2007, 3, 301-316. https://doi.org/10.1166/jbn.2007.041

6. Prabhu, S., Poulose, E.K. Silver nanoparticles: mechanism of antimicrobial action, synthesis, medical applications, and toxicity effects. International Nano Letters 2012, 32. https://doi.org/10.1186/2228-5326-2-32 7. Savithramma, N.; Linga Rao, M.; Rukmini, K.; Suvarnalatha Devi, P. Antimicrobial activity of silver nanoparticles synthesized by using medicinal plants. International Journal of ChemTech Research 2011, 3 , 1394-1402. https://pdfs.semanticscholar.org/a482/f5f6f29aff65a1c82f692cde97c0884ba997.pdf

8. Parashar, V.; Parashar, R.; Sharma, B.; Pandey, A.C. Parthenium leafe extract mediated synthesis of silver nanoparticles: a novel approach towards weed utilization. Digest Journal of Nanomaterials and Biostructures 2009, 4, 45-50.

http://citeseerx.ist.psu.edu/viewdoc/download?doi=10.1.1.473.7183\&rep=rep1\&type=pdf

9. Krishnaraj, C.; Jagan, E.G.; Ramachandran, R.; Abirami, S.M.; Mohan, N.; Kalaichelvan, P.T. (2012)

Effect of biologically synthesized silver nanoparticles on Bacopa monnieri (Linn.) Wettst. plant growth metabolism. Process Biochemistry 2012, 47, 651-658. https://doi.org/10.1016/J.PROCBIO.2012.01.006

10. Cabuzu, D.; Cirja, A.; Puiu, R.; Grumezescu, A.M. (2015) Biomedical applications of gold nanoparticles. Current Topics in Medicinal Chemistry 2015, 15, 1605-1613.

https://doi.org/10.2174/1568026615666150414144750

11. Cai, W.; Gao, T.; Hong, H.; Sun, J. Applications of gold nanoparticles in cancer nanotechnology. Nanotechnology, Science and Applications 2008, 1, 17-32. https://doi.org/10.2147/nsa.s3788

12. Guo, J.; Rahme, K.; He, Y.; Li, L.L.; Holmes, J.; O’Driscoll, C. Gold nanoparticles enlighten the future of cancer theranostics. International Journal of Nanomedicine 2017 12, 6131-6152.

https://doi.org/10.2147/IJN.S140772

13. Sharma, N.; Pinnaka, A.K.; Raje, M.; Fnu, A.; Bhattacharyya, M.S.; Choudhury, A.R. Exploitation of marine bacteria for production of gold nanoparticles. Microbial Cell Factories 2012, 11, 86.

https://doi.org/10.1186/1475-2859-11-86

14. Niazi, J.H., Gu, M.B. (2009) Toxicity of metallic nanoparticles in microorganisms - A review. In Atmospheric and Biological Environmental Monitoring, Kim, Y.J.; Platt, U.; Gu, M.B.; Iwahashi, H., Eds.; Publisher: Springer, Dordrecht, 2009, pp. 193-206. https://doi.org/10.1007/978-1-4020-9674-7_12 
15. Zinicovscaia, I.; Pavlov, S.S.; Frontasyeva, M.V.; Ivlieva, A.L.; Petritskaya, E.N.; Rogatkin, D.A., Demin, V.A. Accumulation of silver nanoparticles in mice tissues studied by neutron activation analysis. Journal of Radioanalytical and Nuclear Chemistry 2018, 318, 985-989. https://doi.org/10.1007/s10967-018-6193-6 16. Marsalek, B.; Jancula, D., Marsalkova, E.; Mashlan, M.; Safarova, K.; Tucek, J.; Zboril, R.) Multimodal action and selective toxicity of zerovalent iron nanoparticles against cyanobacteria. Environmental Science and Technology 2012, 46, 2316-2323. https://doi.org/10.1021/es2031483

17. Abed, R.M.M.; Dobretsov, S., Sudesh, K. Applications of cyanobacteria in biotechnology. Journal of Applied Microbiology 2009, 106, 1-12. https://doi.o.rg/10.1111/j.1365-2672.2008.03918.x

18. Campanella, L.; Crescentini, G.; Avino, P. Chemical composition and nutritional evaluation of some natural and commercial food products based on Spirulina. Analusis 1999, 27, 533-540.

https://doi.org/10.1051/analusis:1999130

19. Thajuddin, N.; Subramanian, G. Cyanobacterial biodiversity and potential applications in biotechnology. Current Science 2005, 89, 47-57.

https://pdfs.semanticscholar.org/98e1/4c455aa390fa156350be3b4433421785fec1.pdf

20. Burchardt, A.D.; Carvalho, R.N.; Valente, A.; Nativo, P.; Gilliland, D.; Garcìa, C.P.; Passarella, R.; Pedroni, V.; Rossi, F.; Lettieri, T. Effects of silver nanoparticles in diatom Thalassiosira pseudonana and cyanobacterium synechococcus sp. Environmental Science and Technology 2012, 46, 11336-11344. https://doi.org/10.1021/es300989e

21. Cherchi, C., Gu, A.Z. Impact of titanium dioxide nanomaterials on nitrogen fixation rate and intracellular nitrogen storage in Anabaena variabilis. Environmental Science and Technology 2010, 44, 83028307. https://doi.org/10.1021/es101658p

22. Shuguang, W.; Lawson, R.; Ray, P.C.; Hongtao, Yu. Toxic effects of gold nanoparticles on Salmonella typhimurium bacteria. Toxicology and Industrial Health 2011, 27, 547-554.

https://doi.org/10.1177/0748233710393395

23. Rudic, V.; Gudumac, V.; Bulimaga, V.; Dencicov, L.; Chelbet, V.; Chiriac, T. (2002) Methods of investigation in phycobiotechnology. Publisher: CE USM, Chişinău, Moldova, 2002; 60p. (in Romanian) 24. Britton, G (1995) UV/Visible spectroscopy. In Carotenoids, Britton, G., Liaaen-Jensen, S., Pfander, H., Eds.; Publisher: Birkhauser Verlag, Basel, 1995, Volume 1, pp.13-62

25. Lejaeghere, K., Van Speybroeck, V.; Van Oost, G.; Cottenier, S. Error estimates for solid-state density-functional theory predictions: An overview by means of the ground-state elemental crystals. Critical Reviews in Solid State and Materials Sciences 2014, 39, 1-24.

https://doi.org/10.1080/10408436.2013.772503

26. Novgorodovo, M.I.; Gorshkov, A.I.; Mokhov, A.V. (1981) Native Silver and Its New Structural Modifications. International Geology Review 1981, 23, 485-494. https://doi.org/10.1080/00206818109455083

27. Choi, O.; Hu, Z. Size dependent and reactive oxygen species related nanosilver toxicity to nitrifying bacteria. Environmental Science and Technology 2008, 42, 4583-4588.

https://doi.org/10.1021/es703238h

28. Moreno-Garrido, I.; Pérez, S.; Blasco, J. Toxicity of silver and gold nanoparticles on marine microalgae. Marine Environmental Research 2015, 111, 60-73.

https://doi.org/10.1016/j.marenvres.2015.05.008

29. Yang, X.; Gondikas, A.P.; Marinakos, S.M.; Auffan, M.; Liu, J.; Hsu-Kim, H.; Meyer, J.N. Mechanism of silver nanoparticle toxicity is dependent on dissolved silver and surface coating in caenorhabditis elegans. Environmental Science and Technology 2012 46, 1119-1127. 
https://doi.org/10.1021/es202417t

30. Navarro, E.; Piccapietra, F.; Wagner, B.; Marconi, F.; Kaegi, R.; Odzak, N.; Sigg, L.; Behra, R. Toxicity of silver nanoparticles to Chlamydomonas reinhardtii. Environmental Science and Technology 2008, 42, 8959-8964. https://doi.org/10.1021/es801785m

31. Greulich, C.; Braun, D.; Peetsch, A.; Diendorf, J.; Siebers, B.; Epple, M.; Köller, M. (2012) The toxic effect of silver ions and silver nanoparticles towards bacteria and human cells occurs in the same concentration range. RSC Advances 2012, 2, 6981-6987. https://doi.org/10.1039/c2ra20684f

32. Pinzaru, I.; Coricovac, D.; Dehelean, C.; Moacă, E.A.; Mioc, M.; Baderca, F.; Sizemore, I.; Brittle, S.; Marti, D.; Calina, C.D.; Tsatsakis, A.M.; Şoica, C. Stable PEG-coated silver nanoparticles - A comprehensive toxicological profile. Food and Chemical Toxicology 2018, 111, 546-556. https://doi.org/10.1016/j.fct.2017.11.051

33. Bastos, V.; Ferreira de Oliveira, J.M.P.; Brown, D.; Jonhston, H.; Malheiro, E.; Daniel-da-Silva, A.L.; Duarte, I.F.; Santos, C.; Oliveira, H. The influence of Citrate or PEG coating on silver nanoparticle toxicity to a human keratinocyte cell line. Toxicology Letters 2016, 249, 29-41.

https://doi.org/10.1016/j.toxlet.2016.03.005

34. Pascual García, C.; Burchardt, A.D.; Carvalho, R.N.; Gilliland, D.; António, D.C.; Rossi, F.; Lettieri, T. (2014) Detection of silver nanoparticles inside marine diatom Thalassiosira pseudonana by electron microscopy and focused ion beam. PLoS ONE 2014, 9, e96078. https://doi.org/10.1371/journal.pone.0096078

35. Pletikapić, G.; Žutić, V.; Vinković Vrček, I.; Svetličić, V. (2012) Atomic force microscopy characterization of silver nanoparticles interactions with marine diatom cells and extracellular polymeric substance. Journal of Molecular Recognition 2012, 25, 309-317. https://doi.org/10.1002/jmr.2177 36. Fratoddi, I.; Venditti, I.; Cametti, C.; Russo, M.V. (2015) How toxic are gold nanoparticles? The stateof-the-art. Nano Research 2015, 8, 1771-1799. https://doi.org/10.1007/s12274-014-0697-3

37. Buchman, J.T.; Rahnamoun, A.; Landy, K.M.; Zhang, X.; Vartanian, A.M.; Jacob, L.M.; Murphy, C.J.; Hernandez, R.; Haynes, C.L. Using an environmentally-relevant panel of Gram-negative bacteria to assess the toxicity of polyallylamine hydrochloride-wrapped gold nanoparticles. Environmental Science: Nano 2018, 5, 279-288. https://doi.org/10.1039/c7en00832e

38. Liu, K.; He, Z.; Byrne, H.J.; Curtin, J.F.; Tian, F. (2018) Investigating the role of gold nanoparticle shape and size in their toxicities to fungi. International Journal of Environmental Research and Public Health 2018, 15, 998. https://doi.org/10.3390/ijerph15050998

39. Boda, S.K.; Broda. J.; Schiefer, F.; Weber-Heynemann, J.; Hoss, M.; Simon. U.; Basu, B.; JahnenDechent, W. Cytotoxicity of Ultrasmall Gold Nanoparticles on Planktonic and Biofilm Encapsulated Gram-Positive Staphylococci. Small 2015, 11, 3183-3193. https://doi.org/10.1002/smll.201403014 40. Van Hoecke, K.; De Schamphelaere, K.A.C.; Ali, Z.; Zhang, F.; Elsaesser, A.; Rivera-Gil, P.; Parak, W.J.; Smagghe, G.; Hivard, C.V.; Janssen, C.R. Ecotoxicity and uptake of polymer coated gold nanoparticles. Nanotoxicology 2013, 7, 37-47. https://doi.org/10.3109/17435390.2011.626566 41. Lehmann, A.D.; Parak, W.J.; Zhang, F.; Ali, Z.; Röcker, C.; Nienhaus, G.U.; Gehr, P.; RothenRutishauser, B. Fluorescent-magnetic hybrid nanoparticles induce a dose-dependent increase in proinflammatory response in lung cells in vitro correlated with intracellular localization. Small 2010, 6, 753-762. https://doi.org/10.1002/smll.200901770

42. Tatur, S.; MacCarini, M.; Barker, R.; Nelson, A.; Fragneto, G. Effect of functionalized gold nanoparticles on floating lipid bilayers. Langmuir 2013, 29, 6606-6614. 
13 of 13

https://doi.org/10.1021/la401074y 